\title{
A model for hepatic fibrosis: The competing effects of cell loss and iron on shortened Modified Look-Locker inversion recovery $\mathrm{T} 1$ (shMOLLI-T1) in the liver
}

Elizabeth M Tunnicliffe, $\mathrm{PhD}^{1}$

Rajarshi Banerjee, DPhil ${ }^{1}$

Michael Pavlides, DPhil ${ }^{1,2}$

Stefan Neubauer, $\mathrm{PhD}^{1}$

Matthew D Robson, $\mathrm{PhD}^{1}$

1. University of Oxford Centre for Clinical Magnetic Resonance Research (OCMR), Radcliffe Department of Medicine, University of Oxford, John Radcliffe Hospital, Oxford, UK

2. Translational Gastroenterology Unit, University of Oxford, Oxford, UK

Corresponding author: Elizabeth M Tunnicliffe, University of Oxford Centre for Clinical Magnetic Resonance Research (OCMR), University of Oxford, Level 0, John Radcliffe Hospital, Oxford, OX3 9DU, UK. E-mail: elizabeth.tunnicliffe@cardiov.ox.ac.uk.

Grant Support: This research was funded by the National Institute for Health Research (NIHR) Oxford Biomedical Research Centre based at The Oxford University Hospitals Trust at the University of Oxford. The views expressed are those of the author(s) and not necessarily those of the NHS, the NIHR or the Department of Health. We also acknowledge funding from the UK Department of Health.

Financial interest: EMT, RB and MDR are authors of a patent relating to this work (GB1304728.7). RB, SN and MDR are directors of Perspectum Diagnostics. EMT, RB, MP, SN and MDR are shareholders in Perspectum Diagnostics.

Running title: Hepatic fibrosis and iron in shMOLLI-T1 


\begin{abstract}
Purpose: Liver T1 values have shown sensitivity to inflammation and fibrosis, but are also affected by hepatic iron content. Modified Look-Locker inversion recovery (MOLLI) T1 measurements are biased by the lower $\mathrm{T} 2$ associated with high iron. The purpose of this work is to propose a simple multi-compartment model of the liver and use Bloch-McConnell simulations to demonstrate the effects of iron and fibrosis on shortened-MOLLI (shMOLLI) T1 measurements.
\end{abstract}

Methods: A tissue model was generated consisting of liver cells and extracellular fluid (ECF), with iron-dependent relaxation rates. Fibrosis was imitated by increasing the ECF proportion. Simulations of the shMOLLI sequence produced a look-up table (LUT) of shMOLLI-T1 for a given ECF fraction and iron content. The LUT was used to calculate ECF(shMOLLI-T1), assuming normal hepatic iron content (HIC), and ECF(shMOLLI-T1,T2*), accounting for HIC determined by $\mathrm{T} 2 *$, for 77 patients and compared to fibrosis assessed by liver biopsy.

Results: Simulations showed that increasing HIC decreases shMOLLI-T1, with an increase in HIC from 1.0 to $2.5 \mathrm{mg} / \mathrm{g}$ at normal ECF fraction decreasing shMOLLI-T1 by $160 \mathrm{~ms}$, while increasing ECF increased ShMOLLI-T1, with an increase of 20\% ECF at normal iron increasing shMOLLI-T1 by $200 \mathrm{~ms}$. Calculated patient ECF(shMOLLI-T1) showed a strong dependence on Ishak score (3.3 $\pm 0.8 \% \mathrm{ECF} /$ Ishak stage) and $1 / \mathrm{T} 2 *(-0.23 \pm 0.04 \% \mathrm{ECF} / \mathrm{Hz})$. However, when iron was accounted for to produce ECF(shMOLLI-T1,T2*), it was independent of HIC but retained sensitivity to Ishak score.

Conclusion: Use of this multi-compartment model of the liver with Bloch-McConnell simulation should enable compensation of iron effects when using shMOLLI-T1 to assess fibrosis.

Keywords: T1 mapping, liver disease, liver MRI 


\section{INTRODUCTION}

MRI has the potential to be a powerful tool in the diagnosis of liver disease. In recent years the measurement of the characteristic relaxation times in liver tissue has become widespread, due to the sensitivity of T2 (1) and T2* (2) to iron accumulation in the liver. In the 1990s, elevated T1 was observed in the livers of patients with cirrhosis $(3,4)$.

More recently, with the development of robust, single breath-hold T1 mapping techniques $(5,6)$, interest in non-contrast enhanced T1-mapping of the liver in patients with cirrhosis has increased (7-9). However, in addition to its effects on T2 and T2*, iron also affects hepatic T1 directly by reducing it (10) and may also influence the measurement of T1 indirectly due to the decrease in T2 (6). Hence studies of the dependence of T1 on fibrosis have tended to exclude patients with iron overload $(8,9)$ despite the high prevalence of this condition. Two patient studies have addressed the additional information that can be gained by combining $\mathrm{T} 2 *$ and $\mathrm{T} 1$ measurements $(11,12)$ qualitatively (presence/absence of iron overload or fibrosis/inflammation), while two more recent studies have made quantitative use of T1 corrected for iron using methods similar to those presented here (13, 14). There is thus clinical utility in a method which can evaluate fibrosis using T1 measurements in the presence of elevated iron.

Here, we introduce a model used to explore the competing effects of fibrosis and iron on hepatic T1 measured using the modified Look-Locker inversion recovery (MOLLI) method.

\section{MATERIALS AND METHODS}

We propose a four-compartment model of the liver consisting of blood, interstitium, and two intracellular spaces, semisolid and liquid (15), with volumes, relaxation rates and exchange rates defined by previous literature reports $(1,13,16-27)$. Iron levels and extracellular volume fraction (ECF), used as a proxy for fibrosis, are independently varied, and Bloch-McConnell (28) simulations used to predict the MOLLI-T1 that would be 
measured in each case. We test the model using measurements of hepatic shortened-MOLLI (shMOLLI) T1 (29) and T2* obtained in patients with chronic diffuse liver disease. We compare estimates, based on the model, of the ECF fraction, taking into account only the measured shMOLLI-T1, ECF(shMOLLI-T1), or taking into account the patient's hepatic iron content (HIC) to obtain ECF(shMOLLI-T1,T2*). These ECF values are compared to an assessment of fibrosis by biopsy to test the validity of the model. The results of applying this model allow shMOLLI-T1 to provide a valuable clinical metric and this is shown in Banerjee et al. (13) where some of these data are shown in a clinical context.

\section{Tissue Model}

A diagram of the proposed tissue model is shown in Figure 1. In this model, the liver is divided into four pools of water, mixed on a sub-voxel level: two intra- and two extracellular. Intracellular water is divided into water bound to macromolecules, and thus invisible to conventional MR due to its very short $\mathrm{T} 2$, known as the semi-solid pool, and the MR-visible liquid pool. This enables the inclusion of known magnetisation transfer effects (15) in the model. The extracellular space is divided into interstitial and vascular spaces, filled with plasma and blood, respectively. The very small (<1\%) volume (27) of bile present in the liver is not included in the model. Fibrosis is simulated in the model by increasing the interstitial volume fraction, while iron affects the relaxation rates, R1 and R2, of the compartments. The values for the volume fractions, $v$, relaxation rates, $\mathrm{R} 1$ and $\mathrm{R} 2$, and exchange rates for water exchange from compartment $a$ to compartment $b, k_{a b}$, are defined by the literature, shown in Table 1 and discussed below. In three cases, the literature can be used to justify differing values for a parameter. In these cases, we justify one value for the main simulation but also test the impact of using the alternative values in supplementary simulations (described in Section 2.2.2). 


\section{Volume Fractions}

Pharmacokinetic models of the liver (16) use volume fractions of around $70 \%$ cells, $15 \%$ blood, and $15 \%$ interstitial space for normal liver. Assuming the $\sim 20 \%$ of tissue volume that is non-water (17) is concentrated in the cells, this gives water fractions in cells, blood and interstitium of $60 \%, 20 \%$ and $20 \%$ respectively. This is consistent with whole-liver water volume data based on animal models (18), when the water contained in large vessels is excluded, and gives a normal ECF fraction of $40 \% .7 \%$ of the cellular component is assigned to the semisolid pool, with the remainder forming the intracellular liquid pool (19).

In order to simulate the effect of fibrosis, the interstitial space is allowed to range from 0$95 \%$ of the volume, with the remaining volume divided in a fixed ratio of $4: 1$ into cells and blood, the same ratio as in normal tissue.

$R 2$

The transverse relaxation time for the semisolid pool in the liver at 3T is given by Stanisz et al (19) as $7.7 \mu \mathrm{s}$.

At 1.5T, the in vivo transverse relaxation rate (in s${ }^{-1}$ ) of liver as a function of hepatic iron content (HIC, measured in $\mathrm{mg} \mathrm{Fe} / \mathrm{g}$ dry weight) is given by $(1,2)$ :

$\mathrm{R} 2(1.5 \mathrm{~T})=6.88+26.06 \times(\mathrm{HIC})^{0.701}-0.438 \times(\mathrm{HIC})^{1.402}$.

This is converted to the relaxation rate of liver at $3 \mathrm{~T}$ based on the Monte Carlo simulations reported by Ghugre (20):

$R 2=R 2(1.5 T) \times 1.47-2.2$.

Equations 1 and 2 refer to intact liver tissue. However, Equation 1 was obtained (1) using a biexponential fit (1), with the reported R2 calculated from a weighted average of the relaxation rates calculated from the two exponentials. We thus express the R2 as: 
$R 2(1.5 T)=R 2 L(1.5 T) \times v_{L}+R 2_{E}(1.5 T) \times v_{E}$.

Based on the fact that most diseases have relatively mixed iron deposition (30), we assume that iron deposition is homogeneous between the parenchyma and extracellular space, and that Equation 2 holds for both compartments separately.

The R2 of blood at 3T in the absence of iron deposits is 3.64/s (19), and that of plasma 2.9/s (21). In considering the effect of iron on the extracellular relaxation rates, there is limited data on the relative diffusivities of water in the hepatic intra- and extracellular spaces. In the main simulation we assume that the diffusivity of protons in the extracellular space is higher than in tissue as a whole and close to that of free water, around four times higher than that of intact liver tissue. (We include in a supplementary simulation the case of identical intraand extra-cellular water diffusivities.) Based on the Monte Carlo simulations of Ghugre et al (22) diffusivity close to free water reduces the iron-dependent R2 by $30 \%$. Combining these observations with Equations 1 and 2 we obtain, for the R2 of blood (R2B) and interstitium $(\mathrm{R} 21)$ at 3T:

$\mathrm{R} 2_{\mathrm{B}}=3.64+\left(0.7 \times 26.06 \times(\mathrm{HIC})^{0.701}-0.7 \times 0.438 \times(\mathrm{HIC})^{1.402}\right) \times 1.47$.

$R 2_{I}=2.9+\left(0.7 \times 26.06 \times(H I C)^{0.701}-0.7 \times 0.438 \times(H I C)^{1.402}\right) \times 1.47$.

However, as the two compartments are in fast exchange, as discussed below in Section 2.1.4, we can express the relaxation rate of the extracellular compartment simply as (23):

$$
\begin{aligned}
R 2_{E} & =\left(R 2_{B} V_{B}+R 2_{I} V_{I}\right) / v_{E} \\
& =\left(3.64 v_{B}+2.9 v_{I}\right) / v_{E}+26.82 \times(H I C)^{0.701}-0.451 \times(H I C)^{1.402}
\end{aligned}
$$

Now, assuming a normal extracellular fluid volume fraction of 0.40 for the calibration data of St Pierre et al (1), combining Equations 1, 2, 3 and 6 yields for the intracellular liquid pool component: 
$R 2_{L}=9.3+46.0 \times(H I C)^{0.701}-0.773 \times(H I C)^{1.402}$.

R1

The dependence of longitudinal relaxation rate of liver tissue on HIC at $1.5 \mathrm{~T}$ is given by (24):

$\mathrm{R} 1=\mathrm{R} 1_{0}+0.029 \times \mathrm{HIC}$.

We assign this same R1 dependence on HIC to both cytoplasmic and extracellular R1. The dependence of R1 on iron concentration is treated as being the same at 1.5 and 3T, based on the low field-sensitivity of ferritin R1 (31), reported limited effect of haemosiderin on T1 (32) and low field-dependence of T1 measurements in brain iron-overload (33) (caused by a mixture of ferritin and haemosiderin). $\mathrm{R} 1_{0}$ of the extracellular space, $\mathrm{R} 1_{\mathrm{E}}$, was based on the fast exchange combination of the R1 of blood at $3 \mathrm{~T}, 0.518 / \mathrm{s}(19)$, and of plasma, 0.44/s (21):

$\mathrm{R} 1_{\mathrm{E}}=0.518 v_{\mathrm{B}} / v_{\mathrm{E}}+0.44 v_{\mathrm{I}} / v_{\mathrm{E}}+0.029 \times \mathrm{HIC}$

$\mathrm{R} 1_{0}$ of the liquid intracellular pool is the only fixed free parameter in the model, and is empirically adjusted in the main simulation to $1.361 \mathrm{~Hz}$ (see Table 2 below) such that for normal ECF fraction (40\%) and HIC $(1.0 \mathrm{mg} / \mathrm{g})$ the modelled shMOLLI-T1 is $717 \mathrm{~ms}$, the same as that measured in seven fasted healthy volunteers (13).

$\mathrm{R} 1$ for the bound pool is fixed at $1 \mathrm{~Hz}(15)$, the standard value used in magnetization transfer models.

\section{Exchange}

The exchange rate between liquid and semisolid intracellular compartments, for magnetisation transfer, is set according to the values of Stanisz et al (19). The line-shape used for the bound pool frequency spectrum is a Super-Lorentzian and we model MT using the methods of Robson et al (34). 
The transcytolemmal exchange rate, $k_{\text {cyt }}$, between intracellular free pool and extracellular compartments is set based on the hepatocyte water residence time, $\tau_{h}$, and hepatocyte fraction $v_{h}$ using the two-compartment relation:

$$
k_{\mathrm{cyt}}=\frac{v_{h}}{\tau_{h}}
$$

Then we form the directional first order rate constants based on the volume fractions in our model,

$$
\begin{aligned}
& k_{\mathrm{LE}}=\frac{k_{c y t}}{v_{\mathrm{L}}}, \\
& k_{\mathrm{EL}}=\frac{k_{c y t}}{v_{\mathrm{E}}} .
\end{aligned}
$$

There are two reports in the literature for the lifetime of water intracellularly in the liver.

Bacic et al found a cellular lifetime of $50 \mathrm{~ms}$ in a hepatocyte fraction of $20 \%$, giving $k_{\text {cyt }}$ of $4 / \mathrm{s}$ (35), while Chang et al measured a lifetime of $250 \mathrm{~ms}$ with a volume fraction of $13 \%$, yielding a $k_{\text {cyt }}$ of $0.52 / \mathrm{s}(25)$. This corresponds to a membrane permeability of around $13 \mu \mathrm{m} / \mathrm{s}$, typical for human cells (36), while a value of $4 / \mathrm{s}$ implies a high permeability of $80 \mu \mathrm{m} / \mathrm{s}$, above that of erythrocytes (35). As a result, we use $k_{\mathrm{cyt}}=0.52 / \mathrm{s}$ in the main simulation, with the higher exchange rate used in a supplementary simulation to demonstrate the impact of such a change in model parameters.

There is limited data in the literature on transendothelial exchange between the sinusoids (the blood compartment) and the interstitial space. However, Mandeville et al (26) suggest that exchange is substantial on timescales of $20 \mathrm{~ms}$, implying $k_{\text {end }}$ is of the order of $25 / \mathrm{s}$. A high exchange rate is consistent with the highly fenestrated and discontinuous walls of the sinusoids in the liver (37). We observe that the difference between relaxation rates of the two spaces given by Equations 4, 5 and 8 is independent of iron and fixed at $0.74 / \mathrm{s}$ for R2 
and $0.078 / \mathrm{s}$ for R1, and that these differences, often known as the relaxographic 'shutter speeds' (38) are far smaller than the exchange rate $k_{\text {end. }}$. This satisfies the requirement for the transendothelial exchange to be in the limit of fast exchange (38). Exchange between erythrocytes and plasma is known to be rapid, with intraerythrocyte lifetimes of around $10 \mathrm{~ms}$ (39). We thus treat the water in the blood as a single compartment.

\section{Simulation}

\section{Main simulation}

To facilitate comparison with the patient data, one specific MOLLI variant, shMOLLI (29), was implemented in the numerical simulation of the Bloch-McConnell equations (28). The exact pulse sequence was generated at $1 \mu$ s resolution during RF pulses and $100 \mu$ s temporal resolution between RF pulses. The inversion pulse used was a Hyperbolic Secant (HS1) pulse of 10.24 ms duration, time-bandwidth product of $R=5.48$, peak $B_{1}=750 \mathrm{~Hz}$ and $\beta=3.45$. The short $(0.48 \mathrm{~ms})$ imaging RF pulses were matched to those used on our scanner, with a Gaussian-like shape. Each of the seven images consisted of 90 RF pulses (5 ramp-up pulses, 84 readout and one $\alpha / 2$ flip-up pulse), with the signal sampled at centre of k-space, after the $24^{\text {th }}$ imaging pulse. The complex signal for each image was taken as the transverse magnetisation at a time TE $=1.01 \mathrm{~ms}$ after this pulse. Other relevant parameters were $\alpha=$ $35^{\circ}$ and $T R=2.4 \mathrm{~ms}$. A single R-R interval was used, due to shMOLLI's low heart rate dependence (29), of $900 \mathrm{~ms}$, equivalent to a heart rate of $67 \mathrm{bpm}$. This yielded inversion times, $\mathrm{TI}$, of $0.1,1.0,1.9,2.8,3.7,0.18$ and $0.26 \mathrm{~s}$. The Bloch-McConnell simulations were carried out in Matlab (Mathworks, Natick, MA) using an in-house implementation. The resulting signal magnitudes as a function of TI were fit using the shMOLLI algorithm (29), implemented in C and incorporated into the Matlab simulations using the Matlab C++ API.

The relaxation and exchange rates from Section 2.1 were used as input parameters in the simulations. ECF was varied in 100 equally-spaced steps from $20 \%$ to $100 \%$, and HIC was separately varied in 100 equally-spaced steps from 0.7 to $6.5 \mathrm{mg} / \mathrm{g}$, based on typical ranges 
of HIC seen in patients with viral hepatitis (40) and fatty liver disease (41) in the absence of hereditary haemochromatosis $(\mathrm{HH})$, to produce a table of simulated shMOLLI-T1 values as a function of ECF and HIC. We note that the numerical results presented in Section 3 are specific to the parameters used in these simulations, particularly the RF pulses used for inversion and readout, although we would expect the overall trends to be similar for other shMOLLI and MOLLI implementations.

\section{Supplementary simulations}

In order to account for the variation of some simulation parameters in the literature, and to demonstrate the general relevance of this model, several supplementary simulations were run, with ECF and HIC varied in 20 equally spaced steps between $20 \%$ and $100 \%$, and 0.7 and $6.5 \mathrm{mg} / \mathrm{g}$ respectively. The difference between the table of (sh)MOLLI-T1 values yielded by these simulations and the main simulation was calculated. In addition, the same statistical analysis described in Section 2.4 was run using each of the supplementary (sh)MOLLI-T1 data sets. The supplementary simulations were varied from the main simulation in each of the following ways:

1. Assuming the same diffusivity and thus the same iron-dependence of R2 in the interstitium and blood as in the cells.

2. Using the faster transcytolemmal exchange rate of $4 / \mathrm{s}$.

3. Excluding all exchange and magnetization transfer effects, except the fast exchange between blood and interstitium, from the simulation.

4. Using the original MOLLI method (5) for estimating T1 rather than the shMOLLI (29) method.

The differences between parameters in the main simulation and the supplementary simulations are summarized in Table $2 . R 1_{0}$ was varied for each model variant to ensure that the shMOLLI-T1 for normal ECF and HIC was $717 \mathrm{~ms}$ (13). R10 was not varied between the 
main simulation and the MOLLI simulation; in this case it is only the MR measurement protocol that is varied, not the model itself.

\section{ShMOLLI-MOLLI Comparison data}

In order to test the results of the shMOLLI and MOLLI simulations outlined above, five normal volunteers were scanned on a 3T Tim Trio scanner (Siemens, Erlangen, Germany), giving informed consent in accordance with our institution's ethical practices. In each subject, three shMOLLI-T1 and three MOLLI-T1 maps, all ECG-gated, in the transverse plane of the liver were acquired using the Siemens Work-in-Progress package 561 (WIP 561), with the following parameters: $\mathrm{TR}=2.4 \mathrm{~ms} ; \mathrm{TE}=0.99 \mathrm{~ms} ; \alpha=35^{\circ} ; \mathrm{FOV}=416 \mathrm{~mm}$; slice thickness $8 \mathrm{~mm}$; acquisition matrix 192x112, GRAPPA factor 2 with 24 reference lines. A region of interest (ROI) in the liver of diameter approximately $2 \mathrm{~cm}$ was drawn in an area without obvious blood vessels on each map and the mean shMOLLI-T1 within the ROI calculated. From this, a mean shMOLLI-T1 and a mean MOLLI-T1 for each subject were calculated. The mean difference between these two values was calculated for each subject, and a paired ttest used to test for statistical significance of the difference at the $p<0.05$ level.

\section{Patient data}

As part of ongoing research at our institution, some of which has been previously published $(13,14)$, all patients scheduled for liver biopsy were invited for an MR scan using the same 3T Siemens scanner. The study was approved by our institutional review board and local ethics committee, and all subjects gave written informed consent. Biopsy reporting included assessment of liver fibrosis by the Ishak score (42). ECG-gated ShMOLLI-T1 maps (29) were acquired, again using WIP 561, in the transverse plane through the right lobe of the liver and the spleen. Typical parameters include: $\mathrm{TR}=2.4-2.6 \mathrm{~ms} ; \mathrm{TE}=0.99-1.05 \mathrm{~ms} ; \alpha=35^{\circ} ; \mathrm{FOV}=$ $340 \mathrm{~mm}-420 \mathrm{~mm}$; slice thickness $6 \mathrm{~mm}$; acquisition matrix 192x134-160, dependent on phase FOV, GRAPPA factor 2 with 24 reference lines. In addition, an ECG-gated multi-echo black blood gradient echo sequence with fat saturation was used to generate $5 \mathrm{~T} 2 *$-weighted 
images. Typical parameters were: TR $=26.5 \mathrm{~ms} ; \mathrm{TE}=2.46 \mathrm{~ms}, 7.38 \mathrm{~ms}, 12.30 \mathrm{~ms}, 17.22 \mathrm{~ms}$ $22.14 \mathrm{~ms} ; \alpha=20^{\circ}$; readout FOV 340mm-420mm; acquisition matrix $192 \times 134-160$, dependent on phase FOV; slice thickness 3mm; GRAPPA factor 2 with 35 reference lines. Pixelwise $\mathrm{T} 2 *$ values were calculated by performing a linear fit to the logarithm of the signal amplitudes, except in the case of short $(<7 \mathrm{~ms}) \mathrm{T} 2 *$ values, which were calculated using the signal ratio of the first two echo times. Hepatic lipid content (HLC) was quantified using stimulated echo, breath-hold ${ }^{1} \mathrm{H}$ MR spectroscopy (43), using the integration of the water peak as an internal reference. In this work we express HLC as:

$H L C=F /(W \times \exp (T E \times R 2)+F)$,

where: $\mathrm{F}$ and $\mathrm{W}$ are the area under the fat and water spectroscopic peaks respectively; TE is the spectroscopic echo time, $10 \mathrm{~ms}$ in our experiments; and R2 is the transverse relaxation rate, calculated from Equations 1 and 2, given the HIC calculated using Equation 9 from the ROI drawn on the $2_{2}^{*}$ maps, described below. For the comparison presented here, we selected only patients who:

- $\mathrm{Had} \mathrm{HLC}<7 \%$.

- Had a diagnosis of viral hepatitis or steatohepatitis, diseases which affect the whole liver.

For each subject, a single shMOLLI-T1 and T2* value was produced, by taking the mean in a circular ROI of diameter $2 \mathrm{~cm}$, in segment 8 of the liver and in a location consistent with the spectroscopy voxel, as described by Banerjee at al(13).

The normal volunteers included by Banerjee et al ((13) had shMOLLI-T1 of 719 $\pm 58 \mathrm{~ms}$ (mean \pm standard deviation), and T2* of $19.8 \pm 2.7 \mathrm{~ms}$, corresponding to HIC of $0.99 \pm 0.08 \mathrm{mg} / \mathrm{g}$, within the normal range (44). Based on this range, we split the patients into two groups: those with iron within two standard deviations of the mean measured in the normal 
volunteers, $\mathrm{HIC} \leq 1.15 \mathrm{mg} / \mathrm{g}$, and those with elevated iron relative to this range, i.e. HIC > $1.15 \mathrm{mg} / \mathrm{g}$.

The matrix of simulated shMOLLI-T1 was used as a look-up table, as follows. For each subject the hepatic iron content was calculated using the relation $(2,45)$

$\mathrm{HIC}(\mathrm{mg} / \mathrm{g})=0.202+0.0254 \times(\mathrm{R} 2 *+11) / 2$.

The measured shMOLLI-T1 can be associated with two ECF fractions: one which assumes the patient had normal iron, akin to using the shMOLLI-T1 to assess fibrosis with no information about the patient's iron level, which we call ECF(shMOLLI-T1); and one taking into account the patient's true HIC, called ECF(shMOLLI-T1,T2*). This process is shown in Figure 2.

This can be taken one step further, using ECF(shMOLLI-T1,T2*) to calculate the T1 which we predict would be measured if the patient had normal liver iron $(1.0 \mathrm{mg} / \mathrm{g})$, known as the iron-compensated T1, or CT1, which can be used for comparison with values measured in normal volunteers. The corresponding cT1 in Figure 2 would be $1046 \mathrm{~ms}$, compared with the normal T1 of $717 \mathrm{~ms}$.

\section{Patient data statistics}

All statistics were generated using the Matlab Statistics and Machine Learning Toolbox (Mathworks, Natick, MA). The normal volunteers were excluded from the dataset (as their shMOLLI-T1 values were used to establish the intracellular liquid pool $\mathrm{R} 1_{0}$ in the simulations). The Spearman rank correlation for all subjects between ECF(shMOLLI-T1) and the Ishak (42) score for fibrosis was calculated, and compared to the correlation between ECF(shMOLLI-T1,T2*) and Ishak score. Multiple linear regression was used to test for the dependence of ECF(shMOLLI-T1) and ECF(shMOLLI-T1,T2*) on fibrosis (via Ishak score, included as an ordinal variable) and iron (via $\mathrm{R} 2{ }^{*}$ ). In order to ensure the validity of the linear model, an Anderson-Darling test at the $p>0.1$ level was used to check that the 
residuals were consistent with a normal distribution. Homoscedasticity was ensured by visually inspecting the plot of residuals as a function of a fitted values, and independence of the errors by inspecting the residuals in case order. One-way analysis of variance (Anova) was run on the resulting models. Again, statistical significance was set at $p<0.05$.

\section{RESULTS}

\section{Simulations}

The result of the main simulation of shMOLLI using the Bloch-McConnell equations including exchange and MT, is shown in Figure 3. The simulated ShMOLLI-T1 shows a strong dependence on the iron content. At normal ECF fraction (40\%) shMOLLI-T1 values over a clinically normal (44) range of HIC from $0.7 \mathrm{mg} / \mathrm{g}$ to $1.8 \mathrm{mg} / \mathrm{g}$ range from $760 \mathrm{~ms}$ down to $616 \mathrm{~ms}$. With elevated ECF fraction this difference is even wider: at $60 \%$ ECF fraction shMOLLI-T1 ranges from $983 \mathrm{~ms}$ down to $784 \mathrm{~ms}$.

Figure 4 shows the differences between this main simulation and the four supplementary simulations. SS1, which increased the R2-shortening effect of iron in the extracellular fluid pool by assuming the same water diffusivity intra- and extracellularly, shows a stronger dependence on iron for higher ECF fractions, as would be expected. SS2, in which the transcytolemmal exchange rate was increased, shows small differences with the main simulation of less than 20 ms everywhere except in the case of very low iron and high ECF. SS3, which removes transcytolemmal exchange and magnetisation transfer effects, shows a not dissimilar pattern, although with the change in the opposite direction. The MOLLI simulation shows similar behaviour to the shMOLLI simulations, but the normal (i.e. $40 \%$ ECF, $1 \mathrm{mg} / \mathrm{g}$ HIC) simulated MOLLI-T1, at 758ms, is $41 \mathrm{~ms}$ higher than the normal shMOLLI-T1 of $717 \mathrm{~ms}$. 


\section{ShMOLLI-MOLLI Comparison}

The five volunteers, all male, were aged $32 \pm 9$ years (range $25-48$ ). Their mean shMOLLIT1 was $723 \pm 65 \mathrm{~ms}$ (mean \pm standard deviation) and the mean MOLLI-T1 was $740 \pm 60 \mathrm{~ms}$. The mean intrasubject difference between MOLLI and shMOLLI was $17 \pm 8 \mathrm{~ms}$. The paired t-test showed that this difference was statistically significant, with $p=0.008$.

\section{Patient data}

Data from 77 patients were included in this study, 54 male and 23 female, aged $52 \pm 13$ years (range 26 - 78). The ECF(shMOLLI-T1) values derived from the shMOLLI-T1s measured in patients are shown plotted in Figure 5a, with the patients with elevated iron levels (HIC > $1.15 \mathrm{mg} / \mathrm{g}$ ) shown as black triangles. The seven normal volunteers, 4 female, 3 male, were aged $39 \pm 12$ years (range $27-55$ ), all with body mass index in the normal range of $18-25$. The ECF(shMOLLI-T1) values from these normal volunteers, whose shMOLLI-T1 values were used to set the intracellular liquid pool $\mathrm{R} 1_{0}$ of the simulations, are included in the figures for comparison, but not used in calculation of any of the statistics. Figure $5 b$ shows the result of taking the patients' and volunteers' iron levels into account to calculate ECF(shMOLLI$\left.\mathrm{T} 1, \mathrm{~T}^{*}\right)$, using the look up table generated from the data in Figure 3. Ishak scores of 0-1 are associated with ECF(shMOLLI-T1,T2*) of around 50\%, while Ishak scores between 2 and 5 give average ECF(shMOLLI-T1,T2*) of 55-65\%. An Ishak score of 6 , denoting cirrhosis, is associated with an average ECF(shMOLLI-T1,T2*) of $71 \%$. Figure $5 c$ shows the relation between shMOLLI-T1 and Ishak score, and Figure $5 \mathrm{~d}$ the same comparison between cT1, the T1 we calculate that would have been measured if the patient's iron levels had been normal, and Ishak score, showing the same trend as seen with ECF(ShMOLLI-T1,T2*) towards increased agreement between CT1 values for patients with normal and high HIC, particularly for the large groups of patients with Ishak scores 1-2. 


\section{Patient data statistics}

The overall Spearman correlation between ECF(shMOLLI-T1,T2*) and Ishak score is 0.75 , improved compared to 0.64 for ECF(shMOLLI-T1) and Ishak score. However, 77 patients is not sufficient to demonstrate that this is a statistically significant increase. Table 3 splits the correlation into that for patients with normal iron and those with elevated iron. The correlation coefficient in patients with normal iron is statistically significant and strong for both ECF(shMOLLI-T1) and ECF(shMOLLI-T1,T2*) with Ishak score. ECF(shMOLLI-T1) values for patients with elevated iron are poorly correlated with Ishak score, and the correlation is not statistically significant. Calculating ECF(shMOLLI-T1,T2*) improves the correlation coefficient and the correlation becomes statistically significant.

Table 4 shows the Spearman correlation coefficients for all patients combined, and abnormal iron subjects separately, for ECF(shMOLLI-T1) as well as ECF(shMOLLI-T1,T2*) calculated from the main simulation and the supplementary simulations. It also includes the linear regression coefficients for iron and associated p-values, showing that the statistically significant dependence of ECF(shMOLLI-T1) on iron is removed by all versions of the model used to calculate ECF(shMOLLI-T1,T2*), and that differences between the performance of the main model and those used in the supplementary simulations are small.

\section{DISCUSSION}

Multi-compartment models, consisting of tissue or water environments mixed on a subvoxel level, have often been used to interpret quantitative MRI. Dynamic contrast enhancement (DCE) experiments (38), for example, are commonly interpreted by fitting the time evolution of the signal in the liver and blood to a model function with parameters related to magnetic resonance parameters of the tissue (compartmental T1, T2 and equilibrium magnetisation), pharmacokinetic rate constants, or physiological values (e.g. tissue compartment water lifetimes) $(36,38)$. 
This study takes the opposite approach of constructing a relatively simple multicompartment model of the liver, which reflects changes in iron and which uses increasing ECF as a proxy for fibrosis. Known physiological and MR parameters of the liver and its components are then used to predict the outcome of shMOLLI-T1 experiments based on the Bloch-McConnell equations. This simulated table of shMOLLI-T1 enables us to calculate ECF from shMOLLI-T1 without bias due to iron, ECF(ShMOLLI-T1,T2*), and also to calculate cT1, the T1 that would have been measured if the patient had normal iron levels.

As detailed in the methods section, most of the parameters for the components could be reliably established from the literature, with a few exceptions. The detailed dependence used here of liver R2 and R2* on iron content has been extensively validated $(1,2,24)$, and the dependence of R1 on iron has been validated against biopsy (24). However, there is some freedom in how the iron in the model is distributed between the two compartments. We chose to assume that iron deposition is relatively homogeneous between the parenchyma and extracellular space, based on the fact that most diseases have relatively mixed iron deposition (30). This differs somewhat from the cases used to determine the calibration curves $(1,2)$, which were based on data from patients with transfusional iron overload, in which iron preferentially accumulates first in the Kupffer cells in the reticuloendothelial system surrounding the sinusoidal spaces. However, we note from the Monte Carlo simulations of Ghugre (20) that the presence or absence of iron in the sinusoidal spaces made little difference to the functional form of the R2 and R2* dependence on iron. We infer from this that the exact distribution of iron within the different spaces does not substantially affect the model.

The other possible issue with using R2 calibration of St Pierre et al (1) is that R2 was measured using a single spin echo sequence. In patients with high levels of iron, particularly high levels of haemosiderin (which aggregates into larger particles), R2 measured using a fast spin echo sequence is dependent on echo spacing (46). However, the maximum iron 
level for the patients included in our study was less than $2.5 \mathrm{mg} / \mathrm{g}$. The contribution of aggregate, haemosiderin-like iron at this relatively low level is minimal, much less than $10 \%$ (46). We thus chose not to incorporate any echo-spacing dependence of R2 into the model reported here.

The R2* calibration presented by Wood et al (2) and extended to 3T by Storey et al (45) is based on a somewhat different multi-echo gradient echo acquisition than that used here. Fat saturation was included in our work as the wider study population included patients with high HLC $(13,14)$, a problem unlikely to be encountered in the thalassaemia cohort used in the original R2*-HIC studies. We also included black blood preparation to avoid artefacts arising from flowing blood, which has been shown in the heart to have no significant effect on the measured $\mathrm{T} 2 *$ values while improving reproducibility (47). Finally the echo times were substantially longer than those employed by Wood et al (2), and moderately longer than those used by Storey et al (45). This was primarily because we were not anticipating the high levels of iron overload in our patient population, which was borne out by the maximum HIC of $2.5 \mathrm{mg} / \mathrm{g}$ in the sub-population studied in this paper, with most patients having $\mathrm{T} 2 *$ above $15 \mathrm{~ms}$. The final difference was that we used a linear fit to the logtransformed data, rather than a monoexponential fit with offset (2). While we were careful to avoid strong bias from noise in the later echoes by using just the first two echo times for patients with high HIC, this was subjectively determined. However, any errors due to this linear fitting procedure will have tended to lead to overestimation of the $\mathrm{T} 2 *$ and thus undercorrection in ECF(shMOLLI-T1, T2*) and cT1.

Apart from $\mathrm{R} 1_{0}$, the intracellular $\mathrm{R} 1$ in the absence of iron, there were three parameters that could not easily be determined from the literature: the transcytolemmal and transendothelial exchange rates, and the scaling of the extracellular relaxivities on iron. Supplementary simulations were carried out in order to study the effect of changes in these parameters on the model predictions. As demonstrated in Table 4 and Figure 4, the 
dependence of shMOLLI-T1 on iron and ECF was not strongly affected by any of these variations, despite the wide range of values for $\mathrm{R} 1_{0}$.

There is a relatively large difference between normal simulated MOLLI-T1 and shMOLLI-T1 of $41 \mathrm{~ms}$. This is somewhat surprising, given the close correspondence between MOLLI- and shMOLLI-T1 measurements in the heart at 3T (29). However, the result is somewhat borne out by the difference between shMOLLI and MOLLI T1 values measured in five normal volunteers of $17 \mathrm{~ms}$. In the model, the difference arises because the time constant for transcytolemmal exchange in the liver model of $0.52 / \mathrm{s}$ is very similar to the difference in $\mathrm{R} 1$ between the intra- and extracellular compartments $(0.89 / \mathrm{s})$. It is therefore possible that the disagreement on the size of the difference between the model and in vivo measurement may indicate an error in the transcytolemmal exchange rate used in the simulations. This would not have made a difference to the conclusions of this study, as shown by the small difference between the main simulation and SS2. It does, however raise the interesting question of whether different MOLLI sampling schemes may be affected differently by changes in transcytolemmal exchange rates in the liver.

Other fast T1 mapping sequences exist without MOLLI's sensitivity to T2 (6). However, MOLLI is attractive for hepatic T1 mapping due to its accuracy (48) and is available from at least one commercial vendor. At least two published studies $(7,13)$ have used MOLLI- or shMOLLI-T1 measurements in assessing fibrosis, with other studies also using inversion recovery techniques which are not immune to $T 2$ bias, primarily due to the $T 2$-weighting of adiabatic inversion pulses $(11,48)$. We note that iron still has an effect on native $\mathrm{T} 1$, and will thus act as a confound irrespective of T1 mapping technique. It is also important to observe that even iron levels well within those expected in normal populations (i.e. $<1.8$ $\mathrm{mg} / \mathrm{g}(44))$ cause clinically significant changes in shMOLLI-T1: a change in iron of as little as $0.4 \mathrm{mg} / \mathrm{g}$ leads to a change in ECF(shMOLLI-T1) of $-7 \%$, equivalent to a loss of two Ishak stages. 
A limitation of this study is a lack of independent validation of the model. Phantom validation is challenging: no general multi-compartment tissue phantom exists for MR, although some work has been carried out on multi-compartment perfusion models (49). Similarly, developing phantom models of iron accumulation in the liver is not straightforward (50), due to the complex dependence of R2 on the clustering of ferritin in cells.

The group of patients presented in this paper only had HICs extending to around $2.5 \mathrm{mg} / \mathrm{g}$, as higher HIC in patients with viral hepatitis and steatohepatitis without $\mathrm{HH}$ is relatively uncommon although still relatively prevalent in other study populations $(40,41)$. While there was no obvious trend towards increased error between the linear model and the data at high HIC (data not shown), the portions of Figures 3 and 4 above $2.5 \mathrm{mg} / \mathrm{g}$ should therefore be taken with more caution as indicators of how higher HIC may alter shMOLLI-T1.

The simplicity of the model means that it clearly does not capture all the details of fibrosis development in the liver. Notably, some of the calculated ECF(shMOLLI-T1,T2*) values in cirrhotic livers exceed $80 \%$, when extracellular volume assessed by contrast-enhanced CT does not exceed $50 \%$ (51). This is not wholly surprising: we have assumed that, in fibrosis, all tissue parameters apart from the interstitial volume stay fixed. It is not implausible to imagine that intrinsic intracellular or extracellular relaxation rates change in disease, or that transcytolemmal exchange rates shift. It has also been previously observed that inflammation is known to affect T1 (11), as well as fibrosis. Thus, while we call the parameter ECF(shMOLLI-T1,T2*) because of its origin in this model, it should not be interpreted as strictly referring to the proportion of tissue water contained extracellularly.

We believe that the strongest argument for the validity of the model is the removal of the strong dependence on R2* of shMOLLI-T1 by applying the lookup process to produce the iron-corrected cT1. Because the only fixed free numeric parameter is set by the healthy 
volunteer group, the effect of the model in removing the iron-dependence of the ECF estimate is independent of the patient data.

In conclusion, we have presented a novel, simple tissue model and shown that when combined with Bloch-McConnell simulations it can be used to investigate the competing effects of iron and fibrosis on shMOLLI-T1 measurements. The model can be used to remove the effect of iron on estimates of ECF (a proxy for fibrosis in this model), enabling assessment of fibrosis using T1 measurements in patients with high iron. 


\section{REFERENCES}

1. St Pierre TG, Clark PR, Chua-anusorn W, et al. Noninvasive measurement and imaging of liver iron concentrations using proton magnetic resonance. Blood 2005;105:855861.

2. Wood JC, Enriquez C, Ghugre N, et al. MRI R2 and R2* mapping accurately estimates hepatic iron concentration in transfusion-dependent thalassemia and sickle cell disease patients. Blood 2005;106:1460-1465.

3. Thomsen C, Christoffersen P, Henriksen O, Juhl E. Prolonged T1 in patients with liver cirrhosis: An in vivo MRI study. Magn Reson Imaging 1990;8:599-604.

4. Keevil SF, Alstead EM, Dolke G, Brooks AP, Armstrong P, Farthing MJ. Non-invasive assessment of diffuse liver disease by in vivo measurement of proton nuclear magnetic resonance relaxation times at 0.08 T. Br J Radiol 1994;67:1083-1087.

5. Messroghli DR, Radjenovic A, Kozerke S, Higgins DM, Sivananthan MU, Ridgway JP. Modified look-locker inversion recovery (MOLLI) for high-resolution T1 mapping of the heart. Magn Reson Med 2004;52:141-146.

6. Chow K, Flewitt JA, Green JD, Pagano JJ, Friedrich MG, Thompson RB. Saturation recovery single-shot acquisition (SASHA) for myocardial T1 mapping. Magn Reson Med $2014 ; 71: 2082-2095$.

7. Cassinotto $\mathrm{C}$, Feldis M, Vergniol J, et al. MR relaxometry in chronic liver diseases: Comparison of T1 mapping, T2 mapping, and diffusion-weighted imaging for assessing cirrhosis diagnosis and severity. Eur J Radiol 2015;84:1459-1465.

8. Heye T, Yang SR, Bock M, et al. MR relaxometry of the liver: Significant elevation of T1 relaxation time in patients with liver cirrhosis. Eur Radiol 2012;22:1224-1232. 
9. Kim KA, Park MS, Kim IS, et al. Quantitative evaluation of liver cirrhosis using T1 relaxation time with 3 tesla MRI before and after oxygen inhalation. J Magn Reson Imaging 2012;36:405-410.

10. Wood JC, Otto-Duessel M, Aguilar M, et al. Cardiac iron determines cardiac T2*, T2, and T1 in the gerbil model of iron cardiomyopathy. Circulation 2005;112:535-543.

11. Hoad CL, Palaniyappan N, Kaye $\mathrm{P}$, et al. A study of $\mathrm{T} 1$ relaxation time as a measure of liver fibrosis and the influence of confounding histological factors. NMR Biomed 2015;28:706-714.

12. Henninger B, Kremser C, Rauch S, et al. Evaluation of MR imaging with T1 and T2* mapping for the determination of hepatic iron overload. Eur Radiol 2012;22:2478-2486.

13. Banerjee R, Pavlides M, Tunnicliffe EM, et al. Multiparametric magnetic resonance for the non-invasive diagnosis of liver disease. J Hepatol 2014;60:69-77.

14. Pavlides M, Banerjee R, Sellwood J, et al. Multiparametric magnetic resonance imaging predicts clinical outcomes in patients with chronic liver disease. J Hepatol 2015; In press. Doi: 10.1016/j.jhep.2015.10.009.

15. Henkelman RM, Huang X, Xiang QS, Stanisz GJ, Swanson SD, Bronskill MJ. Quantitative interpretation of magnetization transfer. Magn Reson Med 1993;29:759-766.

16. Schwen LO, Schenk A, Kreutz C, et al. Representative sinusoids for hepatic four-scale pharmacokinetics simulations. PLoS ONE 2015;10:e0133653.

17. Gonzalez F, Bassingthwaighte JB. Heterogeneities in regional volumes of distribution and flows in rabbit heart. Am J Physiol 1990;258:H1012-H1024.

18. Greenway CV, Stark RD. Hepatic vascular bed. Physiol Rev 1971;51:23-65. 
19. Stanisz GJ, Odrobina EE, Pun J, et al. T1, T2 relaxation and magnetization transfer in tissue at 3 T. Magn Reson Med 2005;54:507-512.

20. Ghugre NR. Calibration of Iron-Mediated MRI Relaxation by Monte Carlo Modeling. Ph.D. thesis, University of Southern California, 2008.

21. Rohrer M, Bauer HP, Mintorovitch J, Requardt M, Weinmann HJ. Comparison of magnetic properties of MRI contrast media solutions at different magnetic field strengths. Invest Radiol 2005;40:715-724.

22. Ghugre NR, Wood JC. Relaxivity-iron calibration in hepatic iron overload: Probing underlying biophysical mechanisms using a Monte Carlo model. Magn Reson Med $2011 ; 65: 837-847$.

23. Zimmerman JR, Brittin WE. Nuclear magnetic resonance studies in multiple phase systems: Lifetime of a water molecule in an adsorbing phase on silica gel. J Phys Chem 1957;61:1328-1333.

24. Ghugre NR, Coates TD, Nelson MD, Wood JC. Mechanisms of tissue-iron relaxivity: Nuclear magnetic resonance studies of human liver biopsy specimens. Magn Reson Med 2005;54:1185-1193.

25. Chang Y, Kim YS, Lee SK, et al. MR study of water exchange and cell membrane permeability in rat liver cells using a tissue-specific MR contrast agent. J Korean Soc Magn Reson Med 1998;2:73-82.

26. Mandeville JB, Moore J, Chesler DA, Garrido L, Weissleder R, Weisskoff RM. Dynamic liver imaging with iron oxide agents: Effects of size and biodistribution on contrast. Magn Reson Med 1997;37:885-890. 
27. Blouin A, Bolender RP, Weibel ER. Distribution of organelles and membranes between hepatocytes and nonhepatocytes in the rat liver parenchyma. A stereological study. J Cell Biol 1977;72:441-455.

28. McConnell HM. Reaction rates by nuclear magnetic resonance. J Chem Phys $1958 ; 28: 430-431$.

29. Piechnik SK, Ferreira VM, Dall'Armellina E, et al. Shortened modified look-locker inversion recovery (ShMOLLI) for clinical myocardial T1-mapping at 1.5 and 3 T within a 9 heartbeat breathhold. J Cardiovasc Magn Reson 2010;12:69.

30. Deugnier Y, Turlin B. Pathology of hepatic iron overload. World J Gastroenterol $2007 ; 21: 4755-4760$.

31. Vymazal J, Brooks RA, Zak O, Mcrill C, Shen C, Chiro GD. T1 and T2 of ferritin at different field strengths: effect on MRI. Magn Reson Med 1992;27:368-374.

32. Versluis MJ, Webb AG, van Buchem MA. Detection of cerebral microbleeds: physical principles, technical aspects and new developments. In: Cerebral Microbleeds:

Pathophysiology to Clinical Practice, Werring DJ, editor, Cambridge: Cambridge University Press, pp. 13-21. 2011.

33. Vymazal J, Brooks RA, Baumgarner $\mathrm{C}$, et al. The relation between brain iron and NMR relaxation times: An in vitro study. Magn Reson Med 1996;35:56-61.

34. Robson MD, Piechnik SK, Tunnicliffe EM, Neubauer S. T1 measurements in the human myocardium: the effects of magnetization transfer on the SASHA and MOLLI sequences. Magn Reson Med 2013;70:664-670.

35. Bacic G, Alameda JC Jr, lannone A, Magin R, Swartz H. NMR study of water exchange across the hepatocyte membrane. Magn Reson Imaging 1989;7:411-416. 
36. Strijkers GJ, Hak S, Kok MB, Springer J Charles S, Nicolay K. Three-compartment T1 relaxation model for intracellular paramagnetic contrast agents. Magn Reson Med 2009;61:1049-1058.

37. Granger DN. Capillary exchange. In: Essential Medical Physiology, Johnson LR, editor, San Diego, CA: Academic Press, chapter 16, p. 238. 3rd edition, 2003.

38. Li X, Rooney WD, Springer CS. A unified magnetic resonance imaging pharmacokinetic theory: Intravascular and extracellular contrast reagents. Magn Reson Med 2005;54:1351-1359.

39. Springer CS, Li X, Tudorica LA, et al. Intratumor mapping of intracellular water lifetime: Metabolic images of breast cancer? NMR Biomed 2014;27:760-773.

40. Younossi ZM, Gramlich T, Bacon BR, et al. Hepatic iron and nonalcoholic fatty liver disease. Hepatology 1999;30:847-850.

41. Piperno A, D'Alba R, Fargion S, et al. Liver iron concentration in chronic viral hepatitis: a study of 98 patients. Eur J Gastroenterol Hepatol 1995;7:1203-1208.

42. Ishak K, Baptista A, Bianchi L, et al. Histological grading and staging of chronic hepatitis. J Hepatol 1995;22:696-699.

43. Rial B, Robson MD, Neubauer S, Schneider JE. Rapid quantification of myocardial lipid content in humans using single breath-hold $1 \mathrm{H}$ MRS at 3 tesla. Magn Reson Med 2011;66:619-624.

44. Nuttall KL, Palaty J, Lockitch G. Reference limits for copper and iron in liver biopsies. Ann Clin Lab Sci 2003;33:443-450. 
45. Storey P, Thompson AA, Carqueville CL, Wood JC, de Freitas RA, Rigsby CK. R2* imaging of transfusional iron burden at 3T and comparison with 1.5T. J Magn Reson Imaging 2007;25:540-547.

46. Tang $\mathrm{H}$, Jensen $\mathrm{JH}$, Sammet $\mathrm{CL}$, et al. $\mathrm{MR}$ characterization of hepatic storage iron in transfusional iron overload. J Magn Reson Imaging 2014;39:307-316.

47. He T, Gatehouse PD, Kirk P, et al. Black-blood T2* technique for myocardial iron measurement in thalassemia. J Magn Reson Imaging 2007;25:1205-1209.

48. Kellman P, Hansen MS. T1-mapping in the heart: Accuracy and precision. J Cardiovasc Magn Reson 2014;16:2.

49. Ma X, Gullberg GT, Parker DL. Magnetic resonance imaging verification of a multicompartment perfusion model for a chromatography gel phantom. Magn Reson Imaging $1995 ; 13: 581-598$.

50. Sukerkar PA, Rezvi UG, MacRenaris KW, Patel PC, Wood JC, Meade TJ. Polystyrene microsphere-ferritin conjugates: A robust phantom for correlation of relaxivity and size distribution. Magn Reson Med 2011;65:522-530.

51. Bandula S, Punwani S, Rosenberg WM, et al. Equilibrium contrast-enhanced CT imaging to evaluate hepatic fibrosis: Initial validation by comparison with histopathologic sampling. Radiology 2015;275:136-143. 


\begin{tabular}{lll}
\hline Model parameter & Value & Reference \\
\hline$v_{\mathrm{S}}$ & $0.07\left(1-v_{\mathrm{E}}\right)$ & $(19)$ \\
$\mathrm{R} 2_{\mathrm{S}}\left(\mathrm{s}^{-1}\right)$ & $1 /\left(7.7 \times 10^{-6}\right)$ & $(19)$ \\
$\mathrm{R} 1_{\mathrm{S}}\left(\mathrm{s}^{-1}\right)$ & 1 & $(15)$ \\
$k_{\mathrm{SL}}\left(\mathrm{s}^{-1}\right)$ & $3.52 / v_{\mathrm{S}}$ & $(19)$ \\
$k_{\mathrm{LS}}\left(\mathrm{s}^{-1}\right)$ & $3.52 / v_{\mathrm{L}}$ & $(19)$ \\
$v_{\mathrm{L}}$ & $0.93\left(1-v_{\mathrm{E}}\right)$ & $(19)$ \\
$\mathrm{R} 2_{\mathrm{L}}\left(\mathrm{s}^{-1}\right)$ & $9.3+46.0 \times(\mathrm{HIC})^{0.701}-0.773 \times(\mathrm{HIC})^{1.402}$ & $(1,20)$ \\
$\mathrm{R} 1_{\mathrm{L}}\left(\mathrm{s}^{-1}\right)$ & $1.36+0.029 \times \mathrm{HIC}$ & $(24)$ \\
$k_{\mathrm{LE}}\left(\mathrm{s}^{-1}\right)$ & $0.52 / v_{\mathrm{L}}$ & $(25)$ \\
$k_{\mathrm{EL}}\left(\mathrm{s}^{-1}\right)$ & $0.52 / v_{\mathrm{E}}$ & $(25)$ \\
$v_{\mathrm{I}}$ & Normal $0.2 ;$ simulated from $0-0.95$ & $(16,18)$ \\
$v_{\mathrm{B}}$ & $\left(1-v_{\mathrm{I}}\right) / 4$ & $(16,18)$ \\
$v_{\mathrm{E}}$ & $v_{\mathrm{I}}+v_{\mathrm{B}}$ & $(16,18)$ \\
$\mathrm{R} 2_{\mathrm{E}}\left(\mathrm{s}^{-1}\right)$ & $\left(3.64 v_{\mathrm{B}}+2.9 v_{\mathrm{I}}\right) / v_{\mathrm{E}}+26.82 \times(\mathrm{HIC})^{0.701}-0.451 \times(\mathrm{HIC})^{1.402}$ & $(1,19-22)$ \\
$\mathrm{R} 1_{\mathrm{E}}\left(\mathrm{s}^{-1}\right)$ & $0.518 v_{\mathrm{B}} / v_{\mathrm{E}}+0.44 v_{\mathrm{I}} / v_{\mathrm{E}}+0.029 \times \mathrm{HIC}$ & $(19,22,24)$ \\
\hline
\end{tabular}

Table 1. Simulation parameters for the various compartments in the model shown in Figure

1. See the text for explanations of the parameter choices. The $v$ are all volume fractions and thus unitless. Hepatic iron concentration, HIC, is measured in units of mg Fe/g dry weight. 


\begin{tabular}{|c|c|c|c|c|c|c|}
\hline Simulation & $\mathrm{R} 2_{\mathrm{E}} / \mathrm{Hz}$ & $\mathrm{k}_{\mathrm{cyt}}$ & $v_{\mathrm{L}}$ & $v_{s}$ & $\begin{array}{l}\text { Sampling } \\
\text { scheme }\end{array}$ & $\begin{array}{l}\mathrm{R} 1_{0} / \mathrm{Hz} \\
{\left[\mathrm{T} 1_{0} / \mathrm{ms}\right]}\end{array}$ \\
\hline Main & $\begin{array}{l}\left(0.216+2.9 v_{1}\right) / v_{E}+26.82 \times(\mathrm{HIC})^{0.701} \\
-0.451 \times(\mathrm{HIC})^{1.402}\end{array}$ & 0.52 & $\begin{array}{l}0.93 x \\
\left(1-v_{E}\right)\end{array}$ & $\begin{array}{l}0.07 x \\
\left(1-v_{E}\right)\end{array}$ & $5(1) 1(1) 1$ & $\begin{array}{l}1.361 \\
{[735]}\end{array}$ \\
\hline SS1 & $\begin{array}{l}\left(0.216+2.9 v_{1}\right) / v_{E}+38.31 \times(\mathrm{HIC})^{0.701} \\
-0.644 \times(\mathrm{HIC})^{1.402}\end{array}$ & - & - & - & - & $\begin{array}{l}1.263 \\
{[792]}\end{array}$ \\
\hline SS2 & - & 4 & - & - & - & $\begin{array}{l}1.238 \\
{[808]}\end{array}$ \\
\hline SS3 & - & 0 & $1-v_{E}$ & 0 & - & $\begin{array}{l}1.613 \\
{[620]}\end{array}$ \\
\hline MOLLI & - & - & - & - & $3(3) 3(3) 5$ & $\begin{array}{l}1.361 \\
{[735]}\end{array}$ \\
\hline
\end{tabular}

Table 2. Changes in simulation parameters for the supplementary simulations. Dashes indicate that the parameters are the same as in the main simulation. Note that $R_{2 L}$ is also altered in SS1 via Equation 3. Both MOLLI sampling schemes involve three inversion pulses. The first number indicates the number of heartbeats on which single shot images are acquired after the first inversion pulse, with the bracketed number indicating the number of further heartbeats' recovery before the next inversion pulse is executed, and so on (48). SSn: supplementary simulation n; HIC: hepatic iron concentration; MOLLI: modified LookLocker inversion recovery. Other symbols are defined in Figure 1. 


\begin{tabular}{lll}
\hline Spearman's R & ECF(shMOLLI-T1) & ECF(shMOLLI-T1,T2*) \\
\hline $\begin{array}{l}\text { HIC } \leq 1.15 \mathrm{mg} / \mathrm{g} \\
(\mathrm{N}=56)\end{array}$ & $0.78^{* *}$ & $0.80^{* *}$ \\
$\mathrm{HIC}>1.15 \mathrm{mg} / \mathrm{g}$ & 0.43 & $0.52^{\dagger}$ \\
$(\mathrm{N}=21)$ & \\
\hline$+\mathrm{p}<0.02 ;{ }^{* *} \mathrm{p}<0.0001$ &
\end{tabular}

Table 3. Spearman's correlation coefficients, $R$, between extracellular fluid fraction (ECF) estimates and Ishak score for patients with normal and elevated iron. HIC: hepatic iron concentration; N: number of patients. 


\begin{tabular}{|c|c|c|c|c|c|c|c|}
\hline & & $\begin{array}{l}\mathrm{R} \text { (all } \\
\text { patients) }\end{array}$ & $\begin{array}{l}\mathrm{R}(\mathrm{HIC}> \\
1.15 \mathrm{mg} / \mathrm{g})\end{array}$ & $\begin{array}{l}\text { Fibrosis } \\
\text { coefficient } \\
\text { (\%ECF/ } \\
\text { Ishak stage) }\end{array}$ & $\begin{array}{l}\text { Iron } \\
\text { coefficient } \\
(\% \text { ECF/ } \\
\text { Hz R2*) } \\
\end{array}$ & $\begin{array}{l}\text { Iron } \\
\text { coefficient } \\
\text { (\% ECF/ } \\
\mathrm{mg} / \mathrm{g} \mathrm{HIC} \text { ) }\end{array}$ & $\begin{array}{l}\text { Iron } \\
\text { Anova } \\
\text { p- } \\
\text { value }\end{array}$ \\
\hline \multicolumn{2}{|c|}{ ECF(shMOLLI-T1) } & $0.64^{* *}$ & 0.43 & $3.5 \pm 0.8 * *$ & $-0.24 \pm 0.04 * *$ & $-19 \pm 3 * *$ & $10^{-8}$ \\
\hline & Main & $0.75^{* *}$ & $0.52+$ & $3.7 \pm 0.9 * *$ & $-0.05 \pm 0.04$ & $-4 \pm 3$ & 0.16 \\
\hline ECF(shMOLLI- & SS1 & $0.76^{* *}$ & $0.59 *$ & $4.2 \pm 1.0 * *$ & $-0.01 \pm 0.04$ & $-0.7 \pm 3$ & 0.84 \\
\hline \multirow[t]{2}{*}{$\left.\mathrm{T} 1, \mathrm{~T} 2^{*}\right)$} & SS2 & $0.75^{* *}$ & $0.55^{\dagger}$ & $3.9 \pm 0.9 * *$ & $-0.06 \pm 0.04$ & $-5 \pm 3$ & 0.11 \\
\hline & SS3 & $0.76^{* *}$ & $0.56^{*}$ & $3.4 \pm 0.8^{* *}$ & $-0.04 \pm 0.04$ & $-3 \pm 3$ & 0.32 \\
\hline
\end{tabular}

$+p<0.02 ;{ }^{*} p<0.01 ;{ }^{* *} p<0.0001$

Table 4. Spearman's correlation coefficients between extracellular fluid fractions (ECF) determined from shortened modified Look-Locker (shMOLLI) T1 values alone, ECF(shMOLLIT1), or shMOLLI-T1 and iron assessed by T2*, ECF(shMOLLI-T1,T2*), and Ishak score, and the coefficient for the effect of iron on ECF from the linear regression. Regression coefficients are shown as estimate \pm standard error. R: Spearman's correlation coefficients for the linear regression; HIC: hepatic iron concentration. 


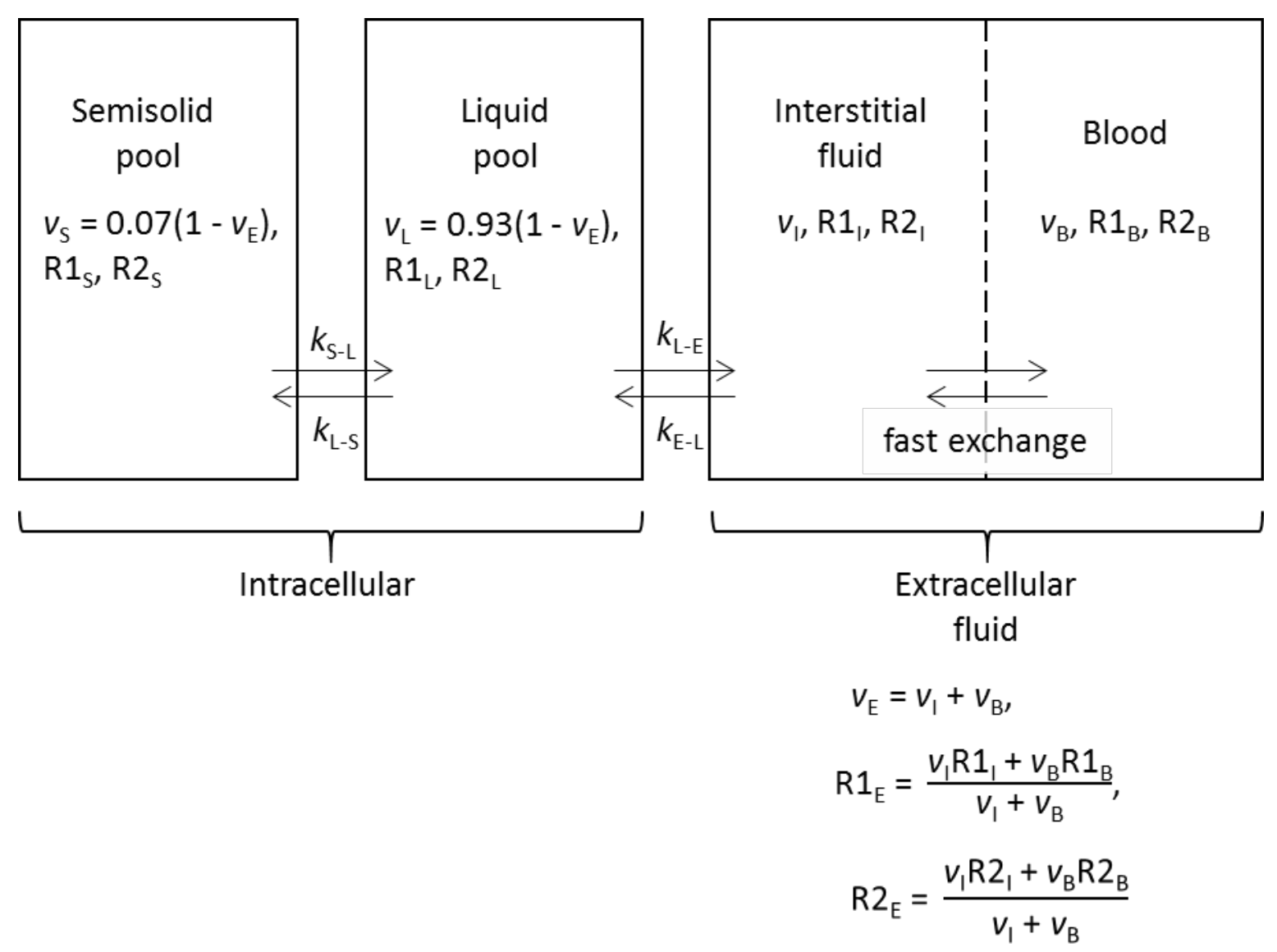

Figure 1. A diagram of the tissue model used in this study. The parameters for each compartment used in the simulation are shown in Table 1. 


\begin{tabular}{|c|c|c|c|c|c|c|c|c|c|}
\hline & \multicolumn{7}{|c|}{ HIC (mg/g) } \\
\hline & & & 1 & 1.25 & 1.5 & 1.75 & 2 & 2.25 & 2.5 \\
\hline \multirow{7}{*}{$\begin{array}{r}E C F \\
\text { fraction }\end{array}$} & & 0.3 & 633 & 603 & 578 & 554 & 535 & 516 & 498 \\
\hline & & 0.4 & 717 & 683 & 654 & 625 & 601 & 578 & 558 \\
\hline & ECF(shMOLLI-T1) & 0.5 & 813 & 774 & 738 & 707 & 678 & 652 & 627 \\
\hline & & 0.6 & 922 & 875 & 834 & 797 & 763 & 732 & 704 \\
\hline & ECF(shMOLLI-T1, T2* & ) 0.7 & 1046 & 991 & 943 & 900 & 860 & 813 & 792 \\
\hline & & 0.8 & 1187 & 1124 & 1069 & 1016 & 972 & 930 & 891 \\
\hline & & 0.9 & 1357 & 1283 & 1216 & 1157 & 1104 & 1053 & 1009 \\
\hline
\end{tabular}

Figure 2. A table showing possible shMOLLI-T1 values in milliseconds for different HIC and ECF fractions. This measured T1 depends on both parameters so that in the case of a measured T1 of $813 \mathrm{~ms}$. If HIC is assumed to be normal, at $1.0 \mathrm{mg} / \mathrm{g}$, we infer an ECF(shMOLLI-T1) of 0.5 , close to the normal value of 0.4 . In this case the $T 2 *$ is $6.7 \mathrm{~ms}$ corresponding to a true HIC of $2.25 \mathrm{mg} / \mathrm{g}$, which means that the obtained ECF(shMOLLI$\left.\mathrm{T} 1, \mathrm{~T}^{*}\right)$ is actually much higher, at 0.7 . 


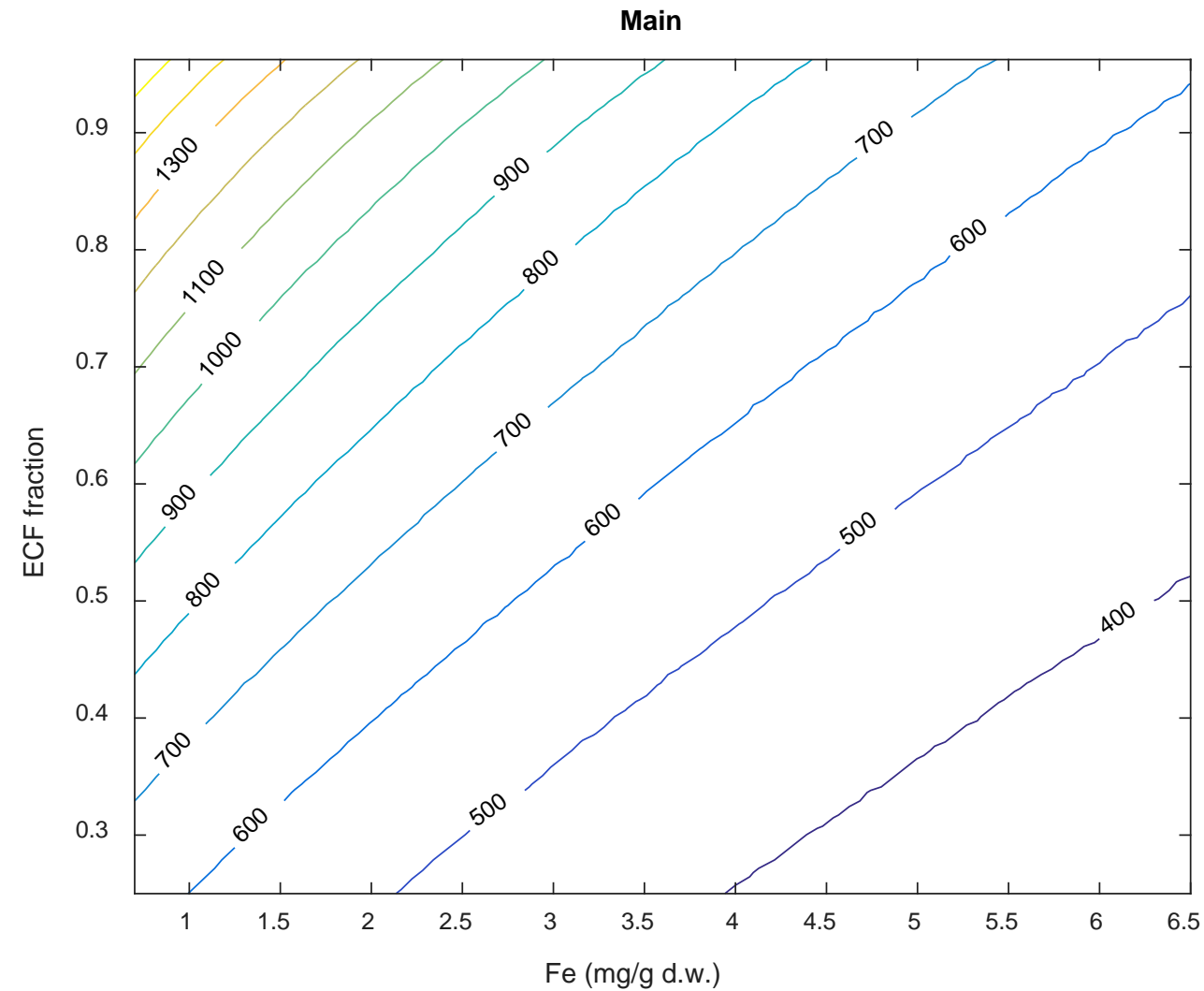

Figure 3. Simulated shMOLLI T1 in milliseconds at 3T as a function of the fluid content (extracellular fluid fraction) and iron level in the liver. 


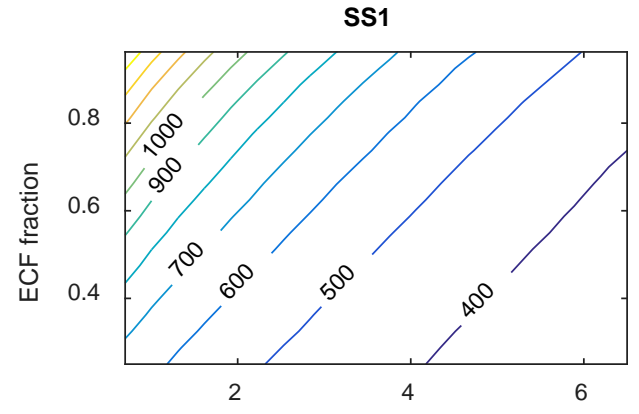

$\mathrm{Fe}$ (mg/g d.w.)

SS2

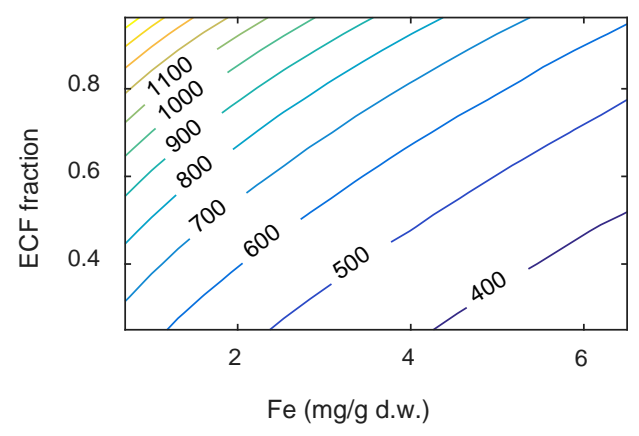

SS3

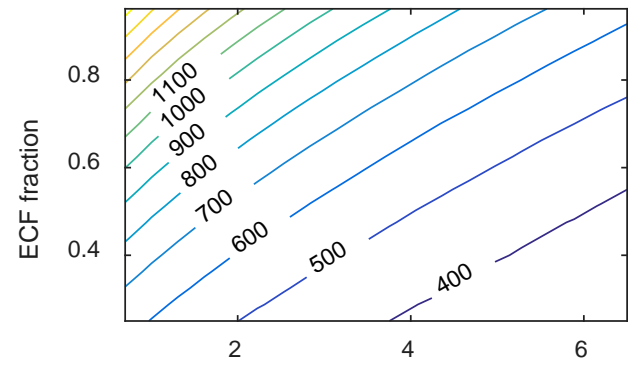

$\mathrm{Fe}(\mathrm{mg} / \mathrm{g}$ d.w.)

MOLLI

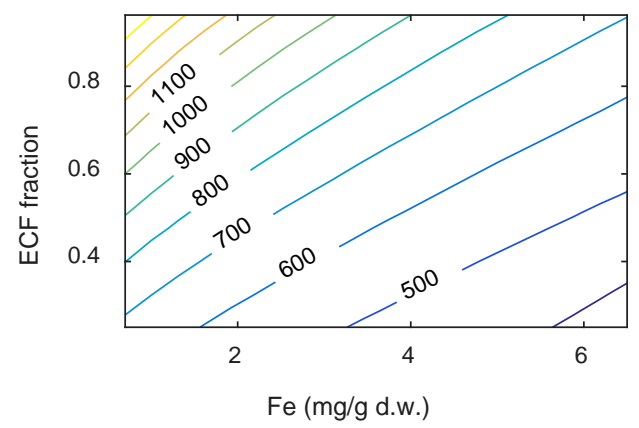

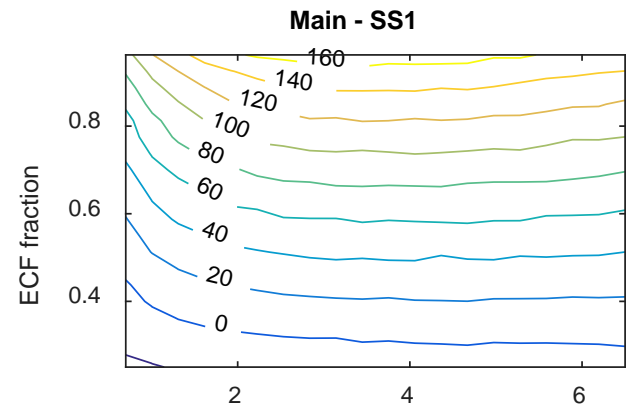

$\mathrm{Fe}(\mathrm{mg} / \mathrm{g}$ d.w.)

Main - SS2
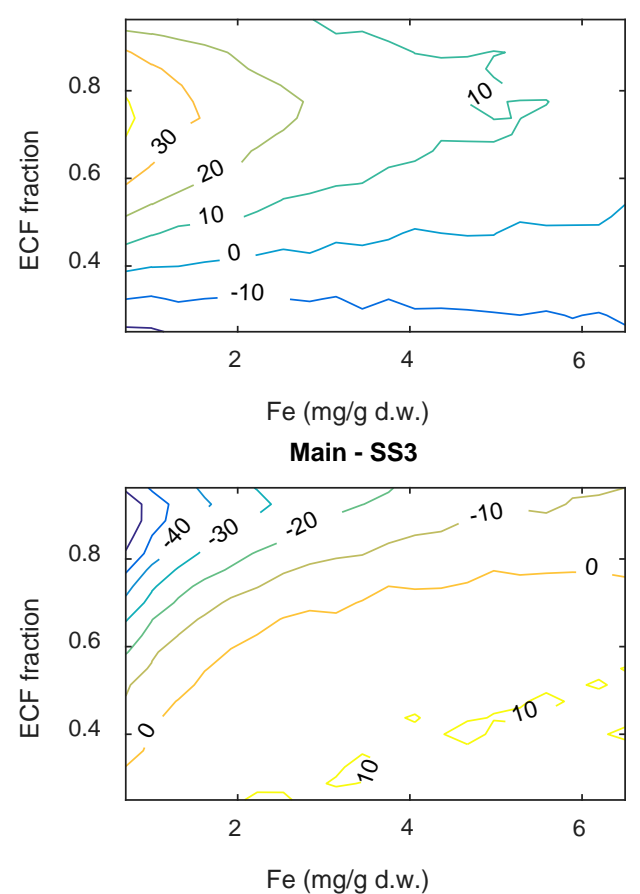

ShMOLLI-MOLLI

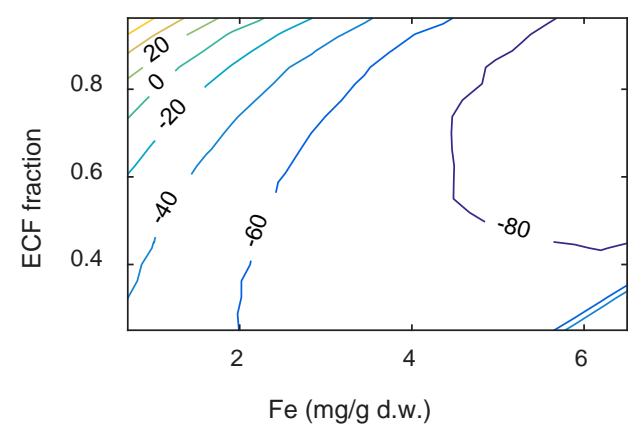

Figure 4. Left: the equivalent of Figure 3 for each supplementary simulation, showing (sh)MOLLI-T1 as a function of ECF and HIC. Right: the difference in (sh)MOLLI-T1 between each simulation and the main (shMOLLI) simulation. 

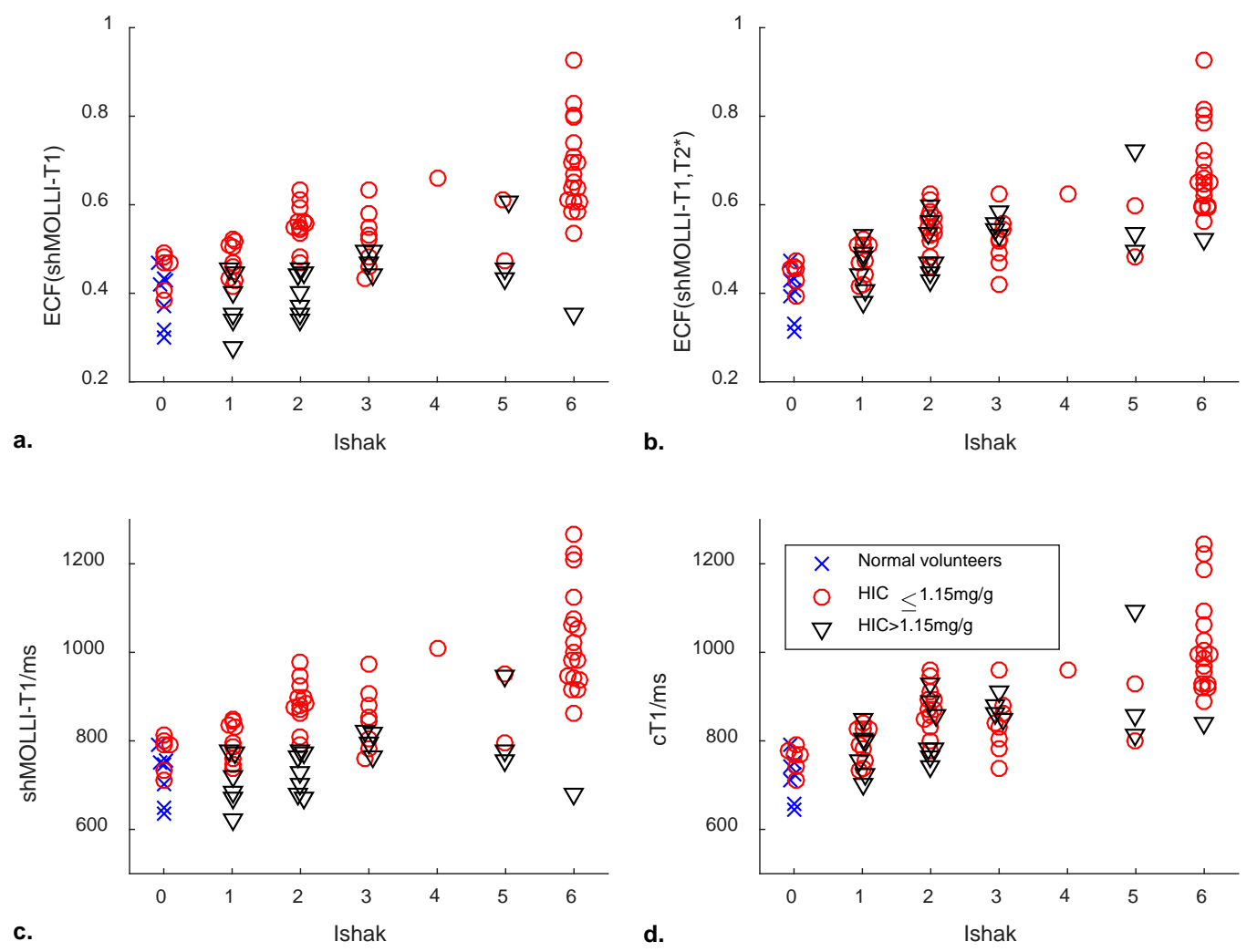

Figure 5. Parts a and $b$ show the relationship between ECF(shMOLLI-T1) and ECF(shMOLLI$\left.\mathrm{T} 1, \mathrm{~T}^{*}\right)$ and fibrosis assessed by Ishak score. Part c shows the correlation of T1 with Ishak score, while part d demonstrates the impact of applying the algorithm shown in Figure 2 to calculate cT1, an iron-compensated ShMOLLI-T1, from the simulated ShMOLLI-T1. 